\title{
MIS TRES VICO
}

\section{Pablo Badillo O'Farrell (Universidad de Sevilla)}

RESUMEN: Se narran tres momentos clave de encuentro con Vico, y los trabajos que el Autor ha producido con relación a ellos en los ámbitos de estudio de las historias de las ideas en filosofía del derecho y en filosofía política. Los tres momentos están representados por tres figurados «Vico». El primero, en 1977, gracias a Francisco Elías de Tejada. El segundo, en 1997, repensando a Vico «veinte años después» y de la mano de Isaiah Berlin. Y el tercero, con su más fructífero acercamiento (al Vico de Voegelin, de Collingwood, de Strauss), entre 1999 (con su participación en el Congreso Internacional sobre Vico, en Sevilla) y 2017 (con su participación en el volumen por el XXV Aniversario de Cuadernos sobre Vico).

Palabras Clave: Vico, $350^{\circ}$ Aniversario, Filosofía política, Historia de las ideas, F. Suárez, F. Elías de Tejada, I. Berlin, E. Voegelin, R.G. Collingwood, L. Strauss, P. Badillo O'Farrell.

\section{My three Vicos}

ABSTRACT: Three key encounters with Vico are here narrated, and the works that the Author has produced in relation to them in the fields of the histories of ideas in philosophy of law and in political philosophy. The three moments are represented by means of three figurative «Vicos». The first one, in 1977, thanks to Francisco Elías de Tejada. The second one, in 1997, rethinking Vico «twenty years later» by the hand of Isaiah Berlin. And the third one, with its most fruitful approach (to Voegelin's Vico, Collingwood's or Strauss's ones), between 1999 (with his contribution to the International Congress on Vico, in Seville) and 2017 (with his contribution to the volume of the XXV Anniversary of Cuadernos sobre Vico).

KeY Words: Vico, 350 th Anniversary, Political philosophy, History of ideas, F. Suárez, F. Elías de Tejada, I. Berlin, E. Voegelin, R.G. Collingwood, L. Strauss, P. Badillo O’Farrell.

\section{MIEI TRE VICO}

RIASSUNTO: Il presente contributo ripercorre i tre momenti chiave dell'incontro con Vico e le opere che l'Autore ha prodotto in proposito negli ambiti di studio delle storie di idee, nella filosofia del diritto e nella filosofia politica. Questi tre momenti sono rappresentati da tre «Vico». Il primo, nel 1977, grazie a Francisco Elías de Tejada. Il secondo, nel 1997, ripensa a Vico «vent'anni dopo» e per mano di Isaiah Berlin. E il terzo, con il suo approccio più fruttuoso (al Vico di Voegelin, di Collingwood e di Strauss), tra il 1999 (con la sua partecipazione al Congresso Internazionale di Vico a Siviglia) e il 2017 (con la sua partecipazione al volume del XXV Anniversario dei Cuadernos sobre Vico).

Parole Chiave: Vico, 350 anniversario, Filosofia politica, Storia delle idee, F. Suárez, F. Elías de Tejada, I. Berlin, E. Voegelin, R.G. Collingwood, L. Strauss, P. Badillo O'Farrell.

Este artículo responde a una invitación expresa por parte de la Dirección de la Revista para este volumen especial por el $350^{\circ}$ Aniversario del nacimiento de G. Vico, habiendo superado los criterios de valoración y del proceso de aceptación. 


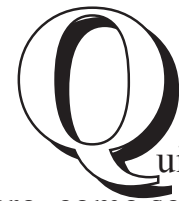

uizás pueda parecer el título de este trabajo aparentemente engañoso, pero, como se desarrollará a lo largo de las páginas siguientes, se encontrará sentido al porqué de él. Por cuestión generacional, tuve la suerte de todavía poder tener y disfrutar de la figura del maestro, que te orientaba y conducía en tu formación, del que podías beber de sus conocimientos y con el que, por último -y si realmente era tal, cual es el caso- podías también discrepar de algunas de sus teorías o perspectivas. Tuve la fortuna, como ya he manifestado en otras muchas sedes, de tener como tal a Don Francisco Elías de Tejada, que, no obstante su titulación de catedrático de Filosofía del Derecho, su vocación - puesta de manifiesto, además, en sus numerosísimas publicaciones- siempre estuvo más orientada hacia la historia de las ideas políticas, a pesar de que su última magna publicación fue el tomo II del Tratado de Filosofía del Derecho, obra lamentablemente truncada por la prematura desaparición de su autor.

Pues bien, en el año 1974 organizó un congreso en la ciudad de Bari dedicado a rendir homenaje y estudio a la figura de Giambattista Vico. Como es bien conocido, por motivos personales, sentimentales e intelectuales estuvo estrechamente ligado a Nápoles, lugar donde encontró a la compañera de su vida y donde vivió más de diez años, repartidos en diversas estancias, para dar culmen a una de sus obras más emblemáticas, cual es el Nápoles Hispánico, publicado en cinco volúmenes, aparte de otras muchas publicaciones menores sobre autores napolitanos, y fue Giambattista Vico uno de aquellos a los que más atención dedicó.

Si se conoce algo el pensamiento de Elías de Tejada, creo que quizás una de las obras para comprender adecuadamente otros planteamientos ulteriores es el libro Las Españas (1948). Su título no debe llevar a confusión con el uso que se está haciendo hoy del mismo rótulo, setenta años después, pero con un planteamiento radicalmente diferente al suyo.

Para Elías de Tejada la riqueza de las Españas consiste justamente en su diversidad, pero a su vez en la existencia de unas metas y unos lazos comunes, ya que, por encima de divisiones administrativas u organizativas, pueden apreciarse rasgos identificativos compartidos y algunos otros superiores que han servido como nexo de unión en la persecución de unos valores e ideas comunes también.

Para él existe un momento histórico, tras la unión de los dos grandes reinos de España, Castilla y Aragón, cual fue la llegada de una determinada dinastía, la habsbúrgica, que favoreció la profunda descentralización política con el reconocimiento implícito de las particularidades de los diversos reinos o regiones que formaban parte de la Monarquía Hispánica. Y para nuestro autor ese es uno de los momentos áureos del Reino de Nápoles. Es asimismo cierto que, debido a situacio- 
nes geopolíticas, se dan las circunstancias para que, debido a ellas, se produzca una auténtica floración de autores hispánicos, entre ellos los napolitanos, que llevaron a cabo una auténtica eclosión teórica sin parangón en muchos siglos. Aunque bien es verdad que a Vico, por motivo del cambio de la dinastía reinante en España, ya no le alcanzaron los períodos áureos o argénteos de la Nápoles anterior -por utilizar los términos de Elías de Tejada-, es bien cierto que todavía pudo formarse en el conocimiento y estudio de los grandes autores españoles de la Segunda Escolástica o Escuela de Salamanca.

Justamente en este sendero, de conocimiento y continuación de las grandes líneas de la Escuela española del Derecho Natural, fue en el que comencé a moverme en mis primeros pasos de acercamiento al filósofo napolitano, por ello es el que pudiéramos denominar mi "primer Vico"; y precisamente por ello presenté a aquel congreso la comunicación con el título «Suárez y Vico», que felizmente ha tenido una gran fortuna editorial. Y digo esto porque tras la primera publicación en 1977, he tenido la suerte de haber vuelto a la cuestión en dos ocasiones ulteriores, una en 1997 y otra el pasado año de 2017, con sendos artículos. Parto de la idea de que buena parte de los planteamientos anti-grocianos de Vico tienen su inspiración en la obra del granadino, y lo convierten en el gran antagonista de los defensores del derecho natural racionalista abstracto, sobre la base de la defensa por ambos -Suárez y Vico- de unos planteamientos que defienden el protagonismo del hombre concreto, con su libertad para elegir el camino a seguir sin cortapisas previas, mientras que el protestantismo, y por ello Grocio, piensan en acciones absolutamente abstracto-racionales del Hombre, de espaldas a la realidad histórico-concreta del ser humano. Estas contraposiciones son las que enfrentan los posicionamientos teóricos de Grocio con los de Vico.

Es asimismo indudable que, a pesar de que esta fuera la línea maestra en la que se desenvolvió mi trabajo de 1977, la perspectiva de los años va produciendo cambios de posiciones en el autor y así, cuando publiqué en 1997 Suárez y Vico, veinte años después en esta misma revista Cuadernos sobre Vico, ya encontré otros senderos por los que discurrir.

En el artículo de 1997 añadí dos elementos que en el primigenio no había destacado suficientemente en su conformación de las grandes líneas de aproximación al derecho, cuales son la reivindicación de la retórica y su condición de heredero de la romanidad. Poner en lugar destacado la tópica fue fundamental para una línea de la filosofía jurídica y ocupó un lugar de privilegio, esencialmente a raíz de la obra de referencia de Theodor Viehweg, Topik und Jurisprudenz, quien considera a Vico como el gran regenerador de la misma en su siglo frente a los que se movían en planteamientos jurídicos abstractos. De esta manera, en la tópica se partía de supuestos de hecho que hacían que el derecho fuera un concreto, basado en los casos factuales que analizaba o de los que partía y que dejaban de 
ser mera proyección de la abstracción racional. A su vez, destaqué una clara herencia romana especialmente referida a la retórica, pero no entendida como saber instrumental o accesorio, sino como capaz, a través de la imaginación, de crear e interpretar el mundo.

Asimismo, en 1997 puse de relieve respecto a las posiciones iniciales la importancia que el hecho jurídico tiene en gran manera para entender el conjunto de su obra, y así se puede apreciar cómo la teoría viquiana del verum-certum se puede apreciar como una clara transposición de supuestos teórico-prácticos del derecho romano. Y lo es en cuanto nuestro autor no piensa en dos esferas claramente diferenciadas, cuales podrían corresponder al jus naturale y al jus civile respectivamente, sino que mantiene que los fines del primero se realizan a través del segundo. Porque, además, referí que cuando Vico habla de verum y de certum en el ámbito del derecho resulta cierto que estaba utilizando conceptos que siempre habían sido subyacentes a la iurisprudentia romana, en el conocimiento de que dicho concepto, tal cual se utilizó entonces, nada tiene que ver con lo que hoy entendemos.

Por último, el pasado año de 2017 , y con motivo del $400^{\circ}$ aniversario del fallecimiento de Francisco Suárez, fui invitado a participar en el volumen homenaje publicado por los Anales de la Cátedra Francisco Suárez de Granada, y dedicado a la figura de tan egregio pensador. En este último artículo, en cierta forma se hizo compatible esta primera línea de aproximación al pensamiento viquiano con la segunda, que se produjo en la mitad de los años Ochenta del pasado siglo.

En aquellos años andaba yo envuelto en la preparación del concurso para la cátedra de Filosofía del Derecho, Moral y Política, y lógicamente uno de los ejercicios al que más tiempo y dedicación debía prestar era al que se conocía en aquella lejana época como escrito de habilitación, aunque tal vez no fuera esta su rotulación administrativa exacta. Dicho escrito consistía en un trabajo inédito de investigación, al modo aproximado de la Habilitationschrift alemana y que, en ciertos casos, era publicado posteriormente a modo de libro. En la preparación de este trabajo me acerqué a un autor inglés que, posteriormente, se ha convertido en un autor muy considerado filosóficamente en nuestro país y yo diría que también en alguien casi icónico, pero que en el meridiano de los años Ochenta era casi desconocido en nuestro país: me refiero a Isaiah Berlin.

Mi trabajo consistió en el desarrollo y controversia sobre la teoría de la libertad en el pensamiento inglés de finales del siglo XX, y partí, en buen manera, del pensamiento berliniano, lo que, lógicamente, me obligó a trabajar no solo en sus obras sobre la libertad sino en intentar comprender las grandes líneas maestras de su pensamiento. Y fue aquí donde descubrí que en sus escritos sobre el pluralismo -concepto básico y esencial del conjunto de su obra- la figura de Vico, al igual que la de Maquiavelo, habían resultado nodales para poder construir su teoría sobre este asunto. Es esta relación entre Vico e Isaiah Berlin la que considero mi "segundo Vico". 
Posteriormente, la figura y la obra de Berlin me atrajeron de forma muy especial y le he dedicado varios libros y un buen número de publicaciones, y cuanto más lo he conocido más cuenta me he dado de la esencialidad de Vico para él, al punto de que ya en sus últimos días y a modo de síntesis vital, al aceptar el título de hijo adoptivo de la ciudad de Santa Margherita Ligure, afirmó que las mayores influencias que reconocía en sus obras eran los escritos de dos autores italianos, un florentino y un napolitano, Maquiavelo y Vico respectivamente.

Es bien conocido cómo Berlin, a lo largo de su obra, buscó esencialmente alcanzar dos metas intelectuales, cuales fueron, por una parte, la consideración y análisis de algunas deficiencias que para él cabían hallarse en los grandes planteamientos de la Ilustración y, por otra parte, la defensa del pluralismo como planteamiento metódico básico sobre el que se sustentó la elaboración de toda su obra teórica. Harto sabido es cómo una de las grandes cuestiones que llamaron la atención de Berlin fue el pensamiento de aquellos autores que, colocándose contra la corriente dominante de su época, intentaron transitar el camino de nuevas sendas. Entre estos pensadores contra-corriente nuestro autor sitúa en lugar de privilegio a Vico, entre otros lugares en un libro que tuvo gran repercusión, Vico and Herder, en el que unía a ambos autores como debeladores de aquellos problemas que fueron los puntos más criticables o dudosos de los planteamientos ilustrados, si bien es manifiesto que hay grandes diferencias entre estos dos autores, ya que poco tienen que ver algunos planteamientos del napolitano con aquellos de carácter prerromántico propios del alemán.

Frente a aquellas construcciones racionales y abstractas sobre las que se sustentaban los grandes conceptos y paradigmas ilustrados, Vico, por ejemplo, frente al concepto de Hombre vuelve al ámbito plural de los hombres concretos, de los seres históricos y particulares, que, aun teniendo un elemento de razón común, son capaces de vivir y contemplar el mundo como algo en lo que ellos tienen mucho que decir en cuanto artífices del mismo y de su plasmación.

En mi artículo, publicado en 2017, Revisita a Suárez y Vico busqué establecer una clara genealogía en la que ambos pudieran ser el comienzo y el fin de la cadena, y Vico el eslabón intermedio que los une. En él analicé los tres posibles niveles del derecho natural enumerados por el granadino, desde el de los principios universalísimos hasta el de los principios más alejados de ellos y próximos a la mutabilidad histórica del hombre, pasando por el intermedio que está formado por las conclusiones inmediatas y racionales derivadas de los primeros principios. Con ello nos percatamos de que en Suárez ya aparece una perspectiva que enfatiza la posible «mutabilidad» de algunos principios del derecho natural, los más cercanos, que establecen la posibilidad de evitar la reiterada crítica al derecho natural por su ahistoricismo, y que, asimismo, abren la posibilidad de conceder a los hombres históricos concretos un protagonismo en el desarrollo de este, como antítesis a las 
visiones de Grocio y otros ilustres iusnaturalistas ilustrados y protestantes que todo lo confiaron a la Razón abstracta. Este es el camino seguido por Vico y es el que también Berlin descubre en el napolitano como inspiración para defender su visión pluralista de la realidad, frente al monismo, que siempre consideró un peligro latente, en el que la condición histórica y particular del hombre es la que sirve como real fundamento de la diversidad de orígenes y fines de la vida.

Por último, he de referir que mi "tercer Vico" es consecuencia del "veneno" viquiano que mi amigo y colega el profesor José Manuel Sevilla nos inoculó a muchos desde 1991, cuando echó a andar el "Centro de Investigaciones sobre Vico", así como la publicación de los Cuadernos sobre Vico, implicándonos en colaborar tanto con contribuciones diversas para la revista como en participar en la organización de diferentes congresos y eventos que ha organizado o co-organizado en nuestra Universidad o en diversas instituciones universitarias extranjeras.

De mis diversas publicaciones en Cuadernos sobre Vico puedo decir que hay un principal hilo conductor en mis trabajos, que es el de la lectura e interpretación de Vico por parte de autores anglosajones contemporáneos.

Así puedo referir dos estudios sobre la incidencia de Vico en la obra de Eric Voegelin, uno en relación con la influencia del napolitano en The New Science of Politics, cuyo mismo título es un homenaje a la Scienza nuova, considerado sobre la base de que ambas obras pueden verse como escritas contra las corrientes de pensamiento dominantes en el momento en que ambas se redactaron.

El segundo artículo publicado sobre la relación entre ambos autores fue bastante novedoso, ya que salió a la luz antes de la publicación en lengua original de la History of Political Ideas voegeliniana, y se hizo porque en Italia se dio a la imprenta como un volumen independiente el apartado referido a Vico dentro de dicha historia, y fue en el que me basé para la redacción de dicho trabajo.

Otro autor anglosajón que mereció mi atención como receptor de la influencia viquiana fue Robin G. Collingwood. Este interés por dicha cuestión me vino poco después de editar un volumen colectivo bajo el título $R$. G. Collingwood: Historia, Metafísica y Politica. Ensayos e interpretaciones, que vio la luz en 2005 y que me dejó con la inquietud de hasta qué punto era necesario volver a incidir o ampliar la cuestión de la receptio por parte del autor inglés de la filosofía de la historia viquiana. Puede decirse, sin temor a exagerar, que la importancia y el interés de esta no se ha valorado en su debido alcance. Quizás haya influido en ello que, debido a las modas que azotan el mundo académico de forma proverbial, Collingwood no es autor que esté muy de «moda». Esta relativa postergación es lo que ha motivado que dicha relación e incidencia no haya sido tratada con la profusión que merecía.

Finalmente, y en el volumen último publicado de los Cuadernos sobre Vico, salió mi aportación sobre el que denominé El Vico perdido de Leo Strauss, y nació 
siguiendo unos apuntes publicados hace muy pocos años en una revista norteamericana de filosofía política, que por otra parte eran incompletos y mutilados, ya que en los archivos existentes en la Universidad de Chicago no existen más páginas que las publicadas. Estas páginas contienen una especie de guión y borrador de un curso que Strauss pensaba impartir en Chicago con ulterioridad, pero las circunstancias impidieron que dicho curso se diera completo y nunca se publicara.

Estas tres grandes líneas son las que, a lo largo de más de cuarenta años, he seguido en mi diálogo con Vico, que lo han llevado a convertirse en autor importante para mí y que, bien por sí mismo, bien por su reflejo o relación con otros, me ha proporcionado siempre o nuevas líneas de conocimiento o bien inspiración para buscar otras. 
350 